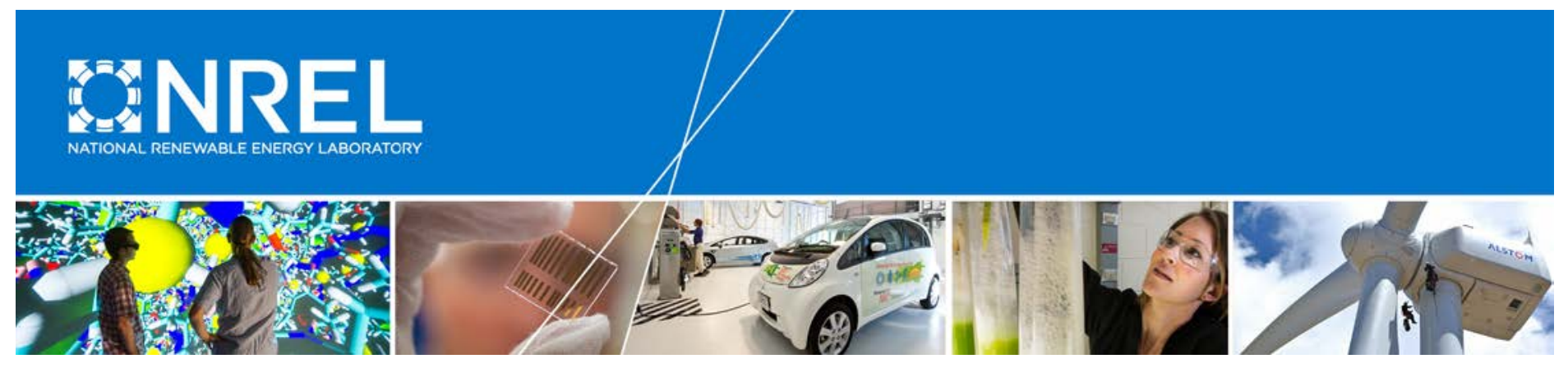

\title{
Evaluating the Role of Pre-Application Reports in Improving Distributed Generation Interconnection Processes
}

Zachary Peterson and Eric Lockhart National Renewable Energy Laboratory

NREL is a national laboratory of the U.S. Department of Energy Office of Energy Efficiency \& Renewable Energy Operated by the Alliance for Sustainable Energy, LLC

This report is available at no cost from the National Renewable Energy Laboratory (NREL) at www.nrel.gov/publications.

Technical Report

NREL/TP-7A40-71765

November 2018 


\title{
Evaluating the Role of Pre-Application Reports in Improving Distributed Generation Interconnection Processes
}

\author{
Zachary Peterson and Eric Lockhart \\ National Renewable Energy Laboratory
}

\author{
Suggested Citation \\ Peterson, Zachary, and Eric Lockhart. 2018. Evaluating the Role of Pre- \\ Application Reports in Improving Distributed Generation Interconnection \\ Processes. Golden, CO: National Renewable Energy Laboratory. \\ NREL/TP-7A40-71765. https://www.nrel.gov/docs/fy19osti/71765.pdf.
}

NREL is a national laboratory of the U.S. Department of Energy Office of Energy Efficiency \& Renewable Energy Operated by the Alliance for Sustainable Energy, LLC

This report is available at no cost from the National Renewable Energy Laboratory (NREL) at www.nrel.gov/publications.

National Renewable Energy Laboratory 15013 Denver West Parkway Golden, CO 80401

303-275-3000 • www.nrel.gov

\section{Technical Report}

NREL/TP-7A40-71765

November 2018

Contract No. DE-AC36-08GO28308 


\section{NOTICE}

This work was authored by the National Renewable Energy Laboratory, operated by Alliance for Sustainable Energy, LLC, for the U.S. Department of Energy (DOE) under Contract No. DE-AC36-08G028308. Funding provided by the U.S. Department of Energy Office of Energy Efficiency and Renewable Energy Solar Energy Technologies Office. The views expressed in the article do not necessarily represent the views of the DOE or the U.S. Government.

This report is available at no cost from the National Renewable Energy Laboratory (NREL) at www.nrel.gov/publications.

U.S. Department of Energy (DOE) reports produced after 1991 and a growing number of pre-1991 documents are available free via www.OSTI.gov.

Cover Photos by Dennis Schroeder: (left to right) NREL 26173, NREL 18302, NREL 19758, NREL 29642, NREL 19795.

NREL prints on paper that contains recycled content. 


\section{Acknowledgements}

The authors thank the Department of Energy's Solar Energy Technologies Office team for its support of this report. For providing comments on drafts of the report, the authors would also like to thank Gerry Bingham (Massachusetts Department of Energy Resources), Tom Key (EPRI), Francisco Flores-Espino (NREL), Jarett Zuboy (consultant), Kristen Ardani (NREL) and Anna Ebers (DOE). 


$\begin{array}{ll}\text { List of } & \text { Acronyms } \\ \text { DER } & \text { distributed energy resources } \\ \text { DOER } & \begin{array}{l}\text { Department of Energy Resources } \\ \text { distributed generation }\end{array} \\ \text { DG } & \text { Database of State Incentives for Renewables and Efficiency } \\ \text { DSIRE } & \text { Federal Energy Regulatory Commission } \\ \text { FERC } & \text { Fitchburg Gas \& Electric } \\ \text { FG\&E } & \text { investor owned utility } \\ \text { IOU } & \text { Interconnection Service Agreement } \\ \text { ISA } & \text { kilowatt } \\ \text { kW } & \text { megawatt } \\ \text { MW } & \text { net energy metering } \\ \text { NEM } & \text { point of interconnection } \\ \text { POI } & \text { photovoltaic } \\ \text { PV } & \text { Small Generator Interconnection Procedures } \\ \text { SGIP } & \text { Western Massachusetts Electric Company } \\ \text { WMECO } & \end{array}$




\section{Executive Summary}

Several tools have emerged in recent years to increase data exchange and transparency in the distributed generation interconnection process with the goal of reducing interconnection costs. One example is pre-application reports. These reports are generated by a utility at the request of prospective interconnection applicants to provide technical information about a specific point of interconnection. Formal pre-application report processes have been established in 12 states at the distribution system level as well as at the transmission level by the Federal Energy Regulatory Commission.

These reports are a relatively low-cost method of informing applicants of grid conditions and potential interconnection limitations early in the interconnection process. Thus, this information may encourage interconnection in locations with little to no detrimental impact to the grid and low interconnection costs. Increasing transparency of these grid conditions may also enable applicants to better plan for interconnection costs and requirements, such as system modifications and complex engineering studies. By providing these benefits, pre-application reports are expected to reduce the number of canceled interconnection applications. This report evaluates this hypothesis by quantifying the impact pre-application report processes have on application approval rate.

To evaluate this hypothesis this analysis uses utility-reported distributed generation interconnection data from four utilities in Massachusetts. The analysis considers a four-year time period before and a five-year period after pre-application report process were implemented. The results indicate that once pre-application reports were required for projects 500 kilowatts and larger the approval rate of applications increased by $24 \%$. This suggests that pre-application reports may decrease the percentage of canceled projects. However, due to data and other limitations, these results do not necessarily connote causation.

This analysis is an important first step and a prerequisite for future analyses regarding the impact of pre-application reports. Rather than providing an inferential statistical analysis (e.g. a multivariate regression analysis) this report provides a descriptive statistical analysis that can be built upon with additional data. Other potential impacts also recognized during this analysis included reducing sunk costs and reducing the number of projects requiring a complex review. Collection of additional data would allow for forming more robust conclusions about these impacts in the future. Such data include circuit-level data, interconnection cost data, nationallevel data, and utility and developer attributes. These data provide necessary context to account for interrelated factors while evaluating pre-application reports. Filling such knowledge gaps ultimately aids decision-makers (e.g. utility executives or regulators) in applying best practices within the industry. 


\section{Table of Contents}

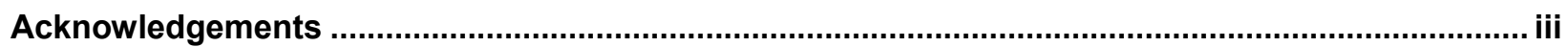

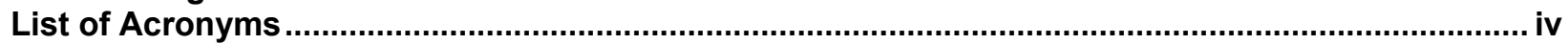

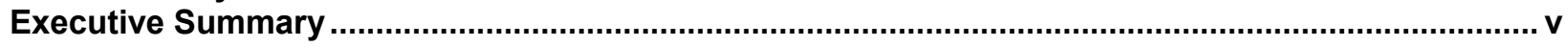

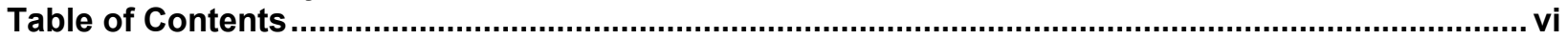

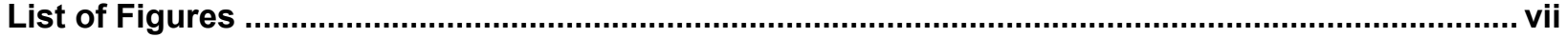

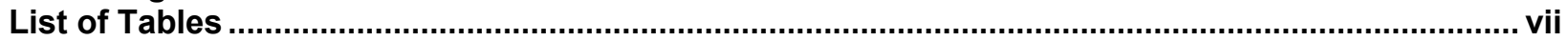

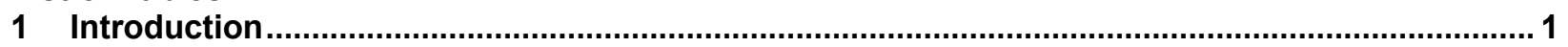

2 Current Pre-Application Report Practices ............................................................................... 3

3 Massachusetts' DER Interconnection and Regulatory Environment.............................................. 7

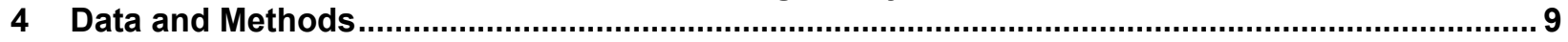

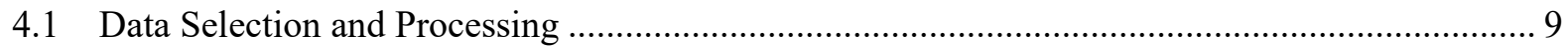

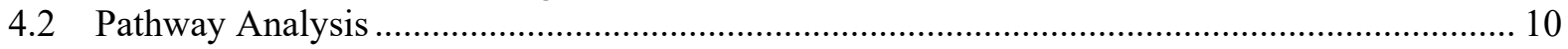

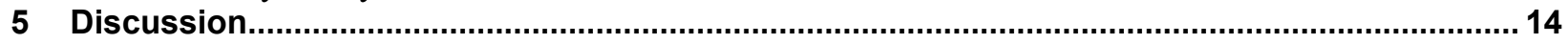

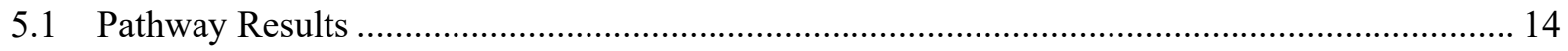

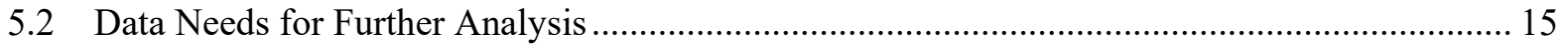

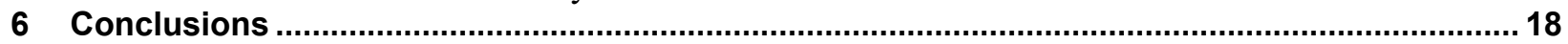

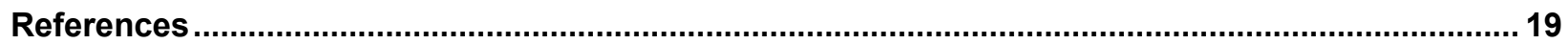

Appendix A. National Grid Pre-application Request ........................................................... 21

Appendix B. DOER Monthly Interconnection Reporting Raw Data Fields .................................. 22

Appendix C. DOER Interconnection Data Cleaning .................................................................. 25

Appendix D. Massachusetts Interconnection Process .............................................................. 26 


\section{List of Figures}

Figure 1. Map of states with formal pre-application processes (as of January 2018) ............................... 3

Figure 2. Massachusetts IOU total installed NEM PV capacity, 2011-2017 ........................................ 8

Figure 3. Percentage of DG applications submitted to each utility, January 2009 - April 2018 ................. 9

Figure 4. Analyzed interconnection application pathways ................................................................ 11

Figure 5. Interconnection pathways for projects $500 \mathrm{~kW}$ and larger with no pre-application report

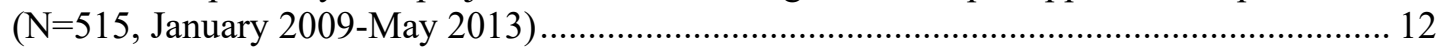

Figure 6. Interconnection pathways for projects $500 \mathrm{~kW}$ and larger with a pre-application report $(\mathrm{N}=928$, May 2013-April 2018)

Figure 7. Changes in percentages of applications along each pathway after pre-application report processes were implemented (percentage in the pre-application case minus percentage in the no-pre-application case) for projects $500 \mathrm{~kW}$ and larger. 13

\section{List of Tables}

Table 1. Alignment with FERC SGIP Pre-Application Report Criteria ................................................. 5

Table 2. State and Federal Fees and Timelines for Pre-Application Reports ........................................... 6

Table 3. Massachusetts Utility Characteristics, 2017 (U.S. Energy Information Administration 2017) ...... 7

Table 4. Massachusetts Interconnection Project Review Paths .............................................................. 10

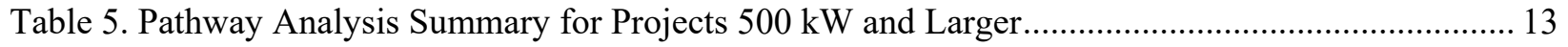

Table 6. Year-to-Year Change in Percentage of Approved Applications ................................................. 15 


\section{Introduction}

The spread of distributed energy resources (DERs), in particular solar photovoltaics (PV), has led to rapid changes in the U.S. electric grid. Interconnecting these resources has been a challenging process for utilities, customers, and project developers. For utilities a common result of this rapid expansion is longer application processing timelines and increased expenses. These challenges can put a strain on customer relationships and hinder utility compliance with regulatory timelines for processing applications. Effective and up-to-date interconnection processes assist utilities with efficiently integrating DERs while maintaining safe, reliable, and affordable service. In addition, streamlined interconnection processes can reduce the financial resources and time required for utilities to interconnect DERs with the grid (Ardani and Margolis 2015). Uniform interconnection standards, hosting capacity maps, and pre-application reports are a few examples of emerging practices in the industry to improve interconnection processes.

A pre-application report provides technical information about a specific point of interconnection (POI) on a utility's distribution or transmission system. These reports are generated by a utility at the request of a prospective interconnection applicant, before an interconnection application is submitted. Appendix A shows an example pre-application request form from National Grid. The information provided in a pre-application report is based on data readily available to the utility but typically unknown to applicants. For example, the report might note the total generation capacity currently in the interconnection queue for the circuit or preexisting system constraints. This information enables interconnection applicants, such as PV project developers, to become aware of potential interconnection limitations or system upgrade costs early in the application process, before making significant financial investments. In the absence of more robust tools like hosting capacity maps or portals with on-demand circuit information, pre-application reports help provide this transparency.

Without the transparency provided by tools like pre-application reports, project developers may resort to submitting multiple, speculative applications to determine the best POI (Coddington et al. 2012). These additional applications consume excessive time and resources on the part of developers and the utility staff who process the applications. If applicants are aware of conditions that may trigger detailed studies or system modifications in advance, they may be able to avoid problematic locations. If the location cannot be changed, the developer can still make a more informed decision about whether or not to pursue the project before initiating the application process. Thus, it logically follows that pre-application report processes help reduce the number of canceled applications, whether they are speculative or due to overburdening unexpected interconnection costs. Although anecdotal evidence suggests that pre-application report processes provide benefits to utilities and interconnection applicants, the impacts have yet to be quantified (Bingham 2018).

This report analyzes the impacts of pre-application reports using utility-reported data on solar PV interconnection applications from investor-owned utilities (IOUs) in Massachusetts. In particular, it focuses on large PV projects (500 kilowatts [kW] and larger). Section 2 provides an overview of pre-application reports and how they are being applied in the United States. Section 3 summarizes the Massachusetts regulatory environment to establish context for the data used in the analysis. Section 4 describes data collection, processing, and limitations as well as the 
analysis process. Finally, Sections 5 and 6 provide discussion and conclusions, including suggestions for future study.

This report is available at no cost from the National Renewable Energy Laboratory at www.nrel.gov/publications. 


\section{Current Pre-Application Report Practices}

Pre-application reports originated in California in 2012 at the distribution-system level. As of January 2018, 11 additional states have published formal rules for pre-application report processes. ${ }^{1}$ The Federal Energy Regulatory Commission (FERC) also enacted pre-application report processes at the transmission level through Order 792 (FERC 2013). Figure 1 shows the states that have implemented pre-application processes as of January 2018.

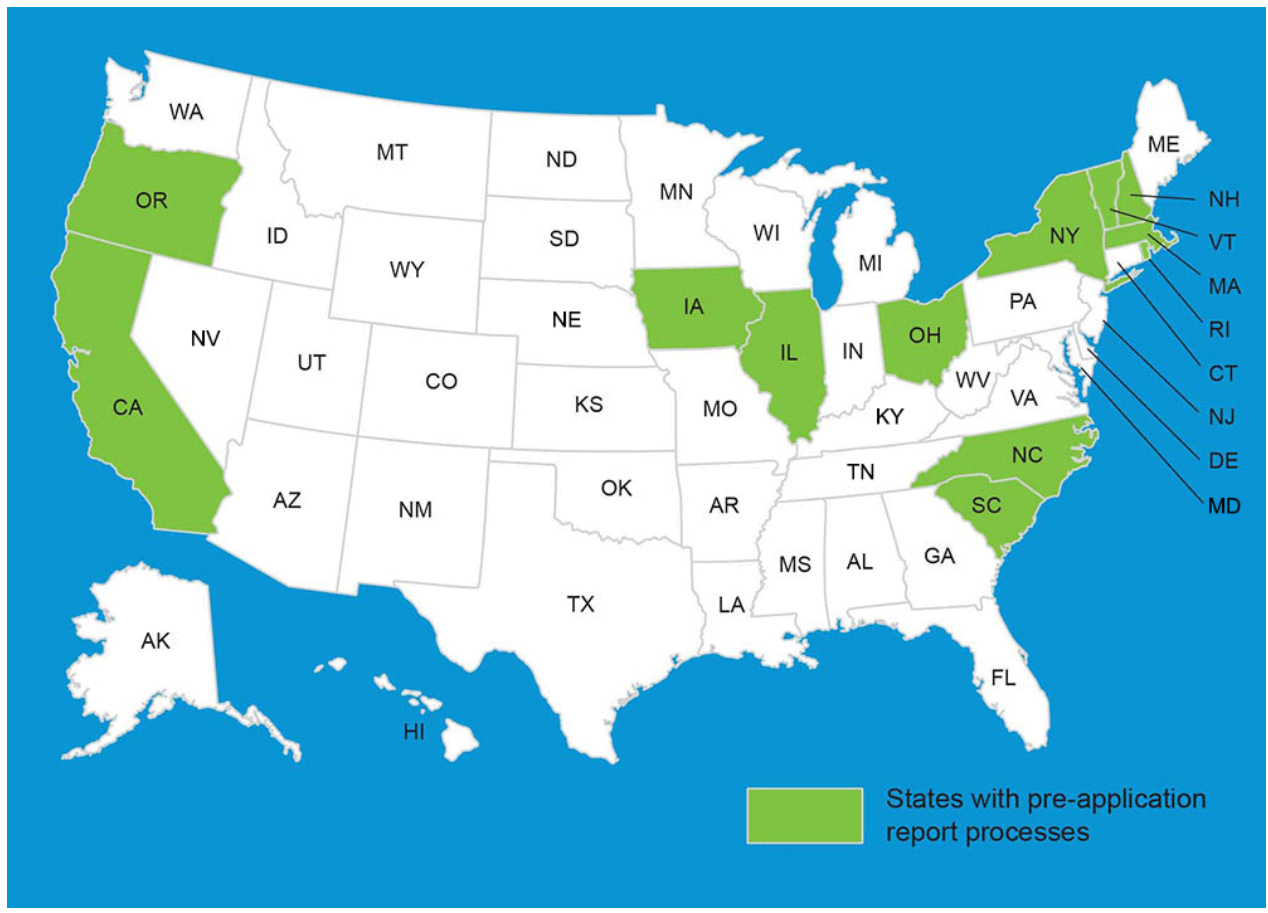

Figure 1. Map of states with formal pre-application processes (as of January 2018)

Pre-application report processes vary from state to state, but the majority align with those established by the Small Generator Interconnection Procedures (SGIP) mandated by FERC Order 792. Typically, a potential interconnection applicant must submit a formal application (e.g., see Appendix A) requesting a pre-application report and provide basic information for the proposed project such as location, design capacity, and technology type. The utility then uses these inputs and preexisting system data to produce the report. The SGIP identifies 13 criteria for utilities to include in the pre-application report, assuming the data are readily available (FERC 2013).

1) Total capacity (in megawatts [MW]) of substation/area bus, bank, or circuit based on normal or operating ratings likely to serve the proposed POI

2) Existing aggregate generation capacity (in $\mathrm{MW}$ ) interconnected to a substation/area bus, bank, or circuit (i.e., amount of generation online) likely to serve the proposed POI

\footnotetext{
${ }^{1}$ This is based on a review of available state interconnection standards and regulatory proceedings conducted in January 2018. It does not include informal mechanisms, or states with utilities that offer this tool voluntarily.
} 
3) Aggregate queued generation capacity (in MW) for a substation/area bus, bank, or circuit (i.e., amount of generation in the queue) likely to serve the proposed POI.

4) Available capacity (in MW) of substation/area bus or bank and circuit likely to serve the proposed POI (i.e., total capacity less the sum of existing aggregate generation capacity and aggregate queued generation capacity).

5) Substation nominal distribution voltage and/or transmission nominal voltage, if applicable.

6) Nominal distribution circuit voltage at the proposed POI.

7) Approximate circuit distance between the proposed POI and the substation.

8) Relevant line section(s) actual or estimated peak load and minimum load data, including daytime minimum load and absolute minimum load, when available.

9) Number and rating of protective devices and number and type (standard or bi-directional) of voltage regulating devices between the proposed POI and the substation/area. Identify whether the substation has a load tap changer.

10) Number of phases available at the proposed POI. If a single phase, distance from the three-phase circuit.

11) Limiting conductor ratings from the proposed POI to the distribution substation.

12) Whether the POI is located on a spot network, grid network, or radial supply.

13) Based on the proposed POI, existing or known constraints such as, but not limited to, electrical dependencies at that location, short circuit interrupting capacity issues, power quality or stability issues on the circuit, capacity constraints, or secondary networks.

The required criteria for pre-application reports in most states aligns with the SGIP.

Table 1 shows how the report criteria requirements for each state compared to the 13 criteria required by the SGIP. 
Table 1. Alignment with FERC SGIP Pre-Application Report Criteria

\begin{tabular}{|c|c|c|c|c|c|c|c|c|c|c|c|c|c|}
\hline FERC SGIP Pre-App Criterion & CA & IA & IL & NC & OH & SC & VT & $\mathbf{R} \mathbf{I}$ & NY & MA & NH & OR & $\begin{array}{l}\text { No. of } \\
\text { States }\end{array}$ \\
\hline Existing Generation Capacity & Yes & Yes & Yes & Yes & Yes & Yes & Yes & Yes & Yes & Yes & No & No & 10 \\
\hline Queued Generation Capacity & Yes & Yes & Yes & Yes & Yes & Yes & Yes & Yes & Yes & Yes & No & No & 10 \\
\hline Distribution Circuit Voltage & Yes & Yes & Yes & Yes & Yes & Yes & Yes & Yes & Yes & Yes & No & No & 10 \\
\hline Number of Phases & Yes & Yes & Yes & Yes & Yes & Yes & Yes & Yes & Yes & Yes & No & No & 10 \\
\hline Substation Distribution Voltage & Yes & Yes & Yes & Yes & Yes & Yes & No & Yes & No & Yes & No & No & 8 \\
\hline Total Capacity & Yes & Yes & Yes & Yes & Yes & Yes & Yes & No & Yes & No & No & No & 8 \\
\hline Circuit Distance & Yes & Yes & Yes & Yes & Yes & Yes & Yes & No & Yes & No & No & No & 8 \\
\hline Peak/Minimum Load Data & Yes & Yes & Yes & Yes & Yes & Yes & Yes & No & Yes & No & No & No & 8 \\
\hline Constraints & Yes & Yes & Yes & Yes & Yes & Yes & Yes & Yes & No & No & No & No & 8 \\
\hline System Configuration & Yes & Yes & Yes & Yes & No & Yes & No & Yes & No & Yes & No & No & 7 \\
\hline Protective Devices & Yes & Yes & Yes & Yes & Yes & Yes & Yes & No & No & No & No & No & 7 \\
\hline Limiting Conductor Ratings & Yes & Yes & Yes & Yes & Yes & Yes & Yes & No & No & No & No & No & 7 \\
\hline Available Capacity & Yes & Yes & Yes & No & Yes & No & Yes & No & No & No & No & No & 5 \\
\hline SGIP Criteria Adopted & 13 & 13 & 13 & 12 & 12 & 12 & 11 & 7 & 7 & 6 & 0 & 0 & \\
\hline
\end{tabular}

Most states require a modest fee (typically ranging from $\$ 300$ to $\$ 750$ ) to compensate the utility for the time taken to prepare the pre-application report. Timelines for producing the reports vary from 10 to 20 business days. For comparison, the FERC SGIP mandates a \$300 fee and a 20-day timeline. New Hampshire and Oregon have less formal processes, providing utilities more flexibility in response time and fee structure.

Table 2 shows the fees and timeline for each state with pre-application report processes. 
Table 2. State and Federal Fees and Timelines for Pre-Application Reports

\begin{tabular}{|l|l|l|}
\hline State & Fee $\mathbf{( \$ )}$ & Timeline (business days) \\
\hline CA & 300 & 10 \\
\hline IA & 300 & 20 \\
\hline IL & 300 & 20 \\
\hline MA & 0 & 10 \\
\hline NC & 300 & 10 \\
\hline NH & -- & -- \\
\hline NY & 750 & 10 \\
\hline OH & 300 & 10 \\
\hline RI & 0 & 10 \\
\hline VT & 300 & 10 \\
\hline OR & $*$ & -- \\
\hline SC & 500 & 20 \\
\hline FERC & 300 & 20 \\
\hline
\end{tabular}

-- None specified

* Per OR legislation: "A person requesting information [under section (1)] must reimburse the public utility for the reasonable costs of gathering and copying the requested information."

Some states have expanded the role of pre-application reports. In California, applicants can purchase multiple supplementary pre-application reports, containing more detailed information, in addition to the standard report. ${ }^{2}$ Although pre-application reports are typically an optional step, in Rhode Island and Massachusetts they are required for projects of $500 \mathrm{~kW}$ or larger. The Massachusetts IOUs have provided monthly data on distributed generation (DG) interconnection applications to the Massachusetts Department of Energy Resources (DOER) since 2009, which appear to be the only detailed data available on interconnection processes completed from the beginning of the application process to the end (i.e., cancelation or an Interconnection Service Agreement [ISA]). These data provide an opportunity for deeper analysis of the interconnection process in Massachusetts.

\footnotetext{
${ }^{2}$ An example of the information included in these reports can be found here:

https://www.pge.com/includes/docs/pdfs/b2b/interconnections/pre-app-request-guide.pdf.
} 


\section{Massachusetts' DER Interconnection and Regulatory Environment}

Massachusetts has operated in a restructured electric utility market since 1997 (DOER 2002). Transmission and distribution are managed primarily by the state's IOUs, while generation falls to competitive suppliers. Massachusetts has four major IOUs: National Grid, NSTAR, Fitchburg Gas \& Electric (FG\&E), and Western Massachusetts Electric Company (WMECO). NSTAR and WMECO are commonly known by their parent company - Eversource Energy — and FG\&E by its parent company-Unitil. Table 3 shows the average number of customers, volume of electricity sales, and revenue for the utilities in 2017.

Table 3. Massachusetts Utility Characteristics, 2017 (U.S. Energy Information Administration 2017)

\begin{tabular}{|l|l|l|l|}
\hline & \multicolumn{1}{|c|}{$\begin{array}{c}\text { Revenue } \\
\text { (thousands) }\end{array}$} & \multicolumn{1}{|c|}{$\begin{array}{c}\text { Sales } \\
\text { (MWh) }\end{array}$} & \multicolumn{1}{c|}{ Customers } \\
\hline FG\&E & $\$ 2,932$ & 13,613 & 20,547 \\
\hline WMECO & $\$ 20,143$ & 111,382 & 159,406 \\
\hline National Grid & $\$ 101,185$ & 537,847 & 758,932 \\
\hline NSTAR & $\$ 103,324$ & 708,089 & 659,241 \\
\hline \multicolumn{2}{ll}{ MWh: megawatt-hour }
\end{tabular}

Massachusetts has implemented several policy measures to support the growth of DERs, particularly PV. The state's renewable portfolio standard, adopted in 2002 and expanded in 2008, requires $15 \%$ of electricity sales be generated from renewable energy sources by 2020 (Database of State Incentives for Renewables and Efficiency [DSIRE] 2017b). This percentage is required to grow by $1 \%$ each subsequent year, with no stated expiration date. In addition, a solar PV carve-out, established in 2010 and expanded in 2014, requires installation of 1,600 MW of solar by 2020 .

Incentives for DG growth also include Massachusetts' net energy metering (NEM) policy. Established in 1982, this policy has been revised several times as caps have been reached and expanded. NEM is currently available to private generating facilities up to $2 \mathrm{MW}$ and public generating facilities up to $10 \mathrm{MW}$ (DSIRE 2017a). The aggregate NEM PV capacity for each distribution company is capped at $8 \%$ (public facilities) and 7\% (private facilities) of the company's highest peak load. PV deployment has grown significantly in this environment over the past decade (Figure 2). 


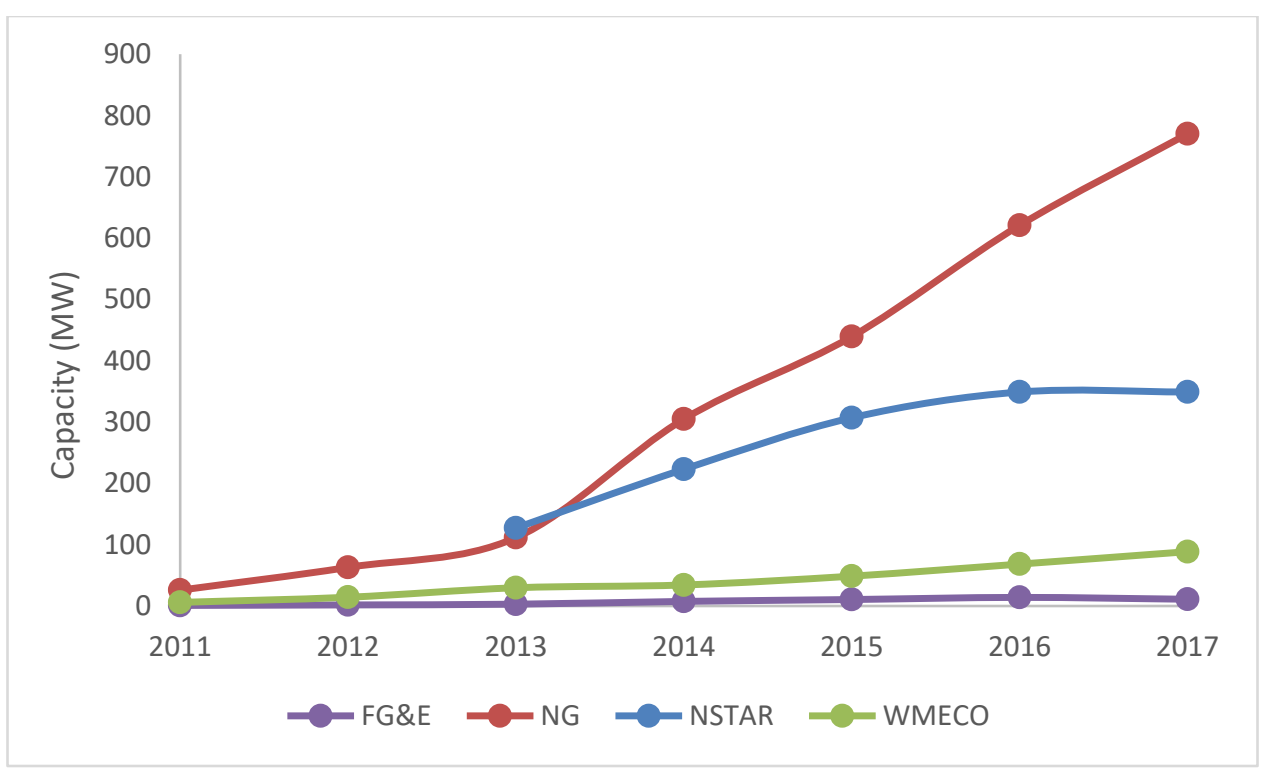

Figure 2. Massachusetts IOU total installed NEM PV capacity, 2011-2017

Massachusetts developed uniform interconnection standards for DG in the early 2000s (Commonwealth of Massachusetts 2005). These standards have subsequently evolved, with the most recent reforms taking place in the early 2010s. These updates primarily focused on clarifying interconnection process requirements, timelines, and compliance monitoring. They also revised technical screens with the intention of allowing more applications to follow the expedited and simplified review pathways (Distributed Generation Interconnection Working Group 2012). Massachusetts' pre-application report process was approved by the Massachusetts Department of Public Utilities on May 1, 2013 (Bingham 2018). This mandate requires all projects of $500 \mathrm{~kW}$ or larger to receive a pre-application report before submitting a formal interconnection application. For projects smaller than $500 \mathrm{~kW}$, pre-application reports are an optional step in the interconnection process. 


\section{Data and Methods}

This analysis uses Massachusetts DOER interconnection process data to explore the impacts of pre-applications on interconnection outcomes. Section 4.1 describes the data used, and Section 4.2 describes the analysis methods.

\subsection{Data Selection and Processing}

The extensive Massachusetts DOER data on proposed projects-including project characteristics, POI characteristics, and review requirements - enable quantification of the impact of pre-application reports. These data are submitted in a standard template, aggregated, and then posted on a DOER-hosted website (DOER 2018). The compiled data cover nearly 8,000 DG applications ( $\sim 5.8 \mathrm{GW})$ submitted between January 2009 and April 2018. Figure 3 shows the percentage of DG applications submitted to each utility in that timeframe.

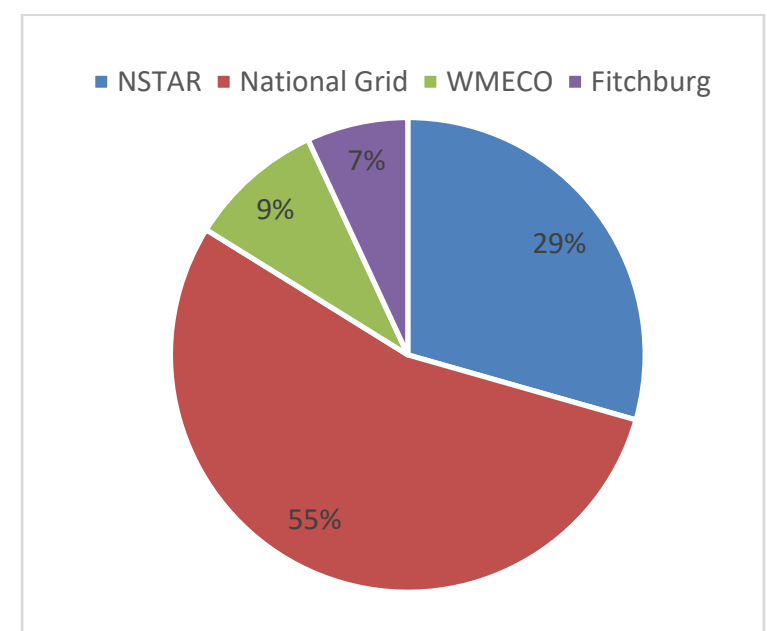

Figure 3. Percentage of DG applications submitted to each utility, January 2009 - April 2018

The utility-reported data for each application include information such as the application date, project design capacity, POI location, studies completed, and project status (see Appendix B for a full list of data included). These data were cleaned, mainly to standardize inputs and reduce ambiguity. For instance, the fuel types "Solar and battery" and "PV and battery" were combined. Appendix $\mathrm{C}$ describes the data cleaning process.

The analysis was confined to PV projects (93\% of applications) and PV-plus-battery projects ( $2 \%$ of applications), which ranged in size from $1.8 \mathrm{~kW}$ to $10 \mathrm{MW}$. The full data set included generator types such as wind, natural gas, and anaerobic digesters. Focusing on PV and PV-plusbattery projects reduces the number of potential factors affecting the results (e.g. differences due to technology characteristics). The raw data were grouped into four project status categories: Authorized, Process Complete, In-Progress, and Canceled. Projects in the Process Complete category had received an ISA but had not been authorized yet. For the purposes of this analysis, these projects provided enough clarity on the progression through the interconnection process to be coded together with Authorized projects. Because the outcomes of the In-Progress applications were uncertain, the projects in this category were omitted from the analysis. 


\subsection{Pathway Analysis}

This analysis evaluates the hypothesis that pre-application report processes decrease the percentage of canceled projects. The first part of this analysis identifies the different review pathways an interconnection application can take before and after the pre-application report processes have been implemented. These pathways differ in complexity depending on the requirement of an impact study, detailed study, and/or system modification. The applications were tracked from start to finish to determine the percentage of projects eventually reaching either ISA or cancellation through these pathways. The results from these scenarios were analyzed to determine the effect pre-application reports had on application approval rate.

The pathways were identified based on Massachusetts' Standards for Interconnection of Distributed Generation (National Grid 2016). Appendix D provides a detailed flow chart of how applications proceed through the process. Applications submitted to the IOUs fall into three separate review pathways based on various system characteristics: Simplified, Standard, or Expedited (Table 4). The DOER data excludes projects undergoing the Simplified process, so only the Expedited and Standard review pathways were included in this analysis.

Table 4. Massachusetts Interconnection Project Review Paths

\begin{tabular}{|c|c|c|}
\hline Simplified & Expedited & Standard \\
\hline $\begin{array}{l}\text { PV and other inverter-based } \\
\text { technologies served by radial } \\
\text { systems, } 15 \mathrm{~kW} \text { or less } 1 \text { - } \\
\text { Phase or up to } 25 \mathrm{~kW} 3 \text {-Phase }\end{array}$ & $\begin{array}{l}\text { Inverter-based systems greater than } 15 \\
\text { kW 1-Phase or greater than } 25 \mathrm{~kW} 3- \\
\text { Phase and other systems of all sizes that } \\
\text { are served by radial systems and meet } \\
\text { other requirements }\end{array}$ & $\begin{array}{l}\text { All projects not eligible } \\
\text { for simplified or } \\
\text { expedited review, } \\
\text { including all systems on } \\
\text { networks }\end{array}$ \\
\hline
\end{tabular}

Figure 4 shows the potential pathways analyzed. Prior to submitting an application, applicants may or may not request a pre-application report. Applications then follow either the Expedited pathway or the Standard pathway. ${ }^{3}$ Applications following the Expedited pathway can reach agreement, be canceled, or be identified as needing a system modification, which is followed by either agreement or cancelation. For the Standard pathway, all applications receive an impact study. Four options can follow the impact study: cancelation, agreement, detailed study, or system modifications without detailed study. Applications needing system modification but no detailed study can be canceled or reach agreement. Projects requiring detailed study can either reach agreement, be canceled, or require system modification. Finally, these projects can either be canceled or reach agreement after system modification.

\footnotetext{
${ }^{3}$ In reality, projects can move from the Expedited to the Standard process as well. The DOER data only noted the final track each application followed, so that pathway was excluded for this analysis.
} 


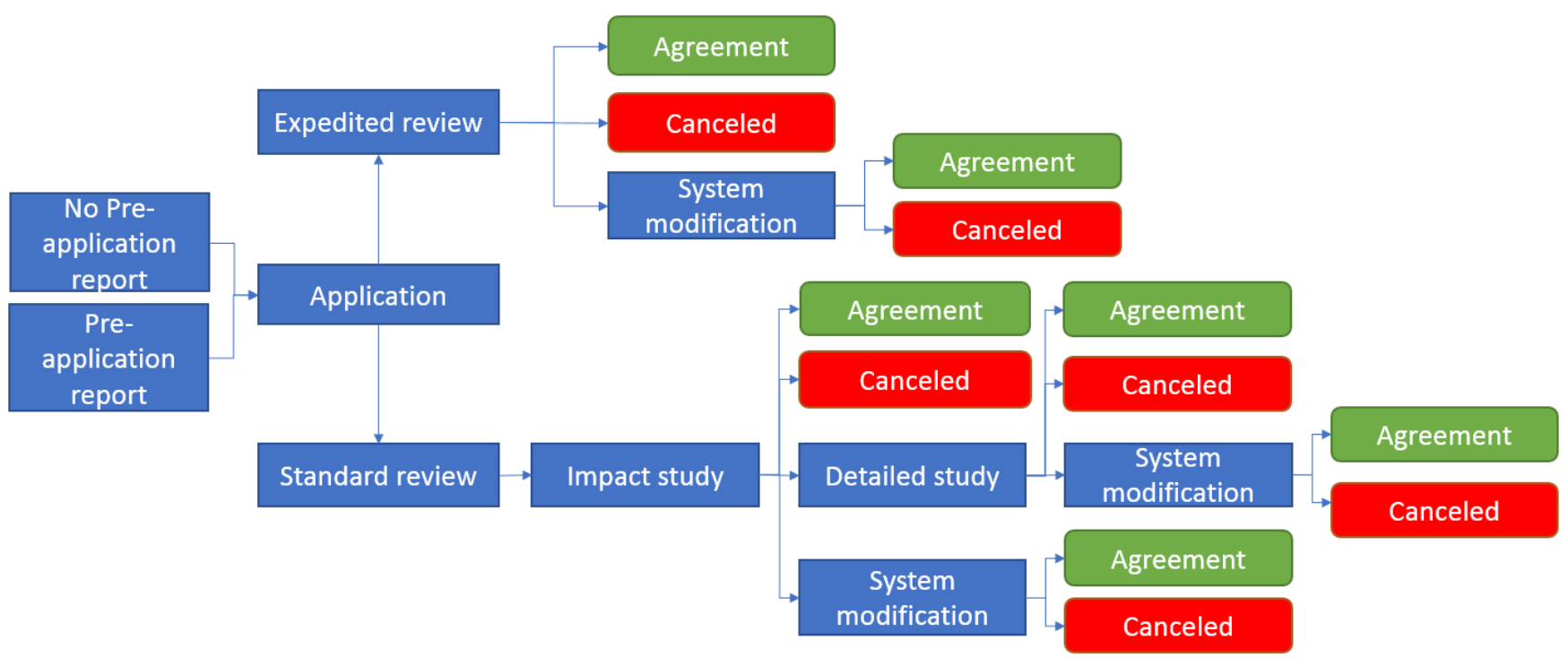

Figure 4. Analyzed interconnection application pathways

The DOER data set does not directly identify which applications received a pre-application report. However, because the pre-application process was implemented May 1, 2013, and all projects $500 \mathrm{~kW}$ and larger must receive a pre-application report, applications for projects of that size submitted after that date were assumed to have received one. Conversely, applications 500 $\mathrm{kW}$ and larger submitted before that date were assumed not to have received one. Applications for projects smaller than $500 \mathrm{~kW}$ were subject to uncertainty because pre-application reports were optional for these projects. As a result, the analysis focused on projects $500 \mathrm{~kW}$ and larger and segmented the analysis into two subsets:

- Projects $500 \mathrm{~kW}$ or larger without a pre-application report (submitted on or before May 1, 2013): 515 applications, $822 \mathrm{MW}$

- Projects $500 \mathrm{~kW}$ or larger with a pre-application report (submitted after May 1, 2013): 928 applications, $1,673 \mathrm{MW}$

Figure 5 shows the percentages of the 515 analyzed applications without a pre-application report following each pathway to agreement or cancelation: $67 \%$ underwent Expedited review, and $33 \%$ underwent Standard review. In total, $67 \%$ of the projects within this group were canceled, while $33 \%$ reached an ISA. In addition, $39 \%$ of these projects required system modifications, but only $6 \%$ required a detailed study. Applications submitted under the Simplified pathway but later transitioned to an Expedited or Standard review are included in the data.

Figure 6 shows the percentages of the 928 analyzed applications with a pre-application report. Compared with the subset of applications with no pre-application report, a lower percentage of applications in the subset with a pre-application report underwent Expedited review (40\% vs. $67 \%$ ) and a higher percentage underwent Standard review (60\% vs. 33\%). The subset with a preapplication report also had a higher percentage reaching agreement (57\% vs. 33\%), a lower percentage being canceled ( $43 \%$ vs. $67 \%$ ), and higher percentages requiring system modifications ( $64 \%$ vs. $39 \%)$ and detailed study (14\% vs. $6 \%)$. 


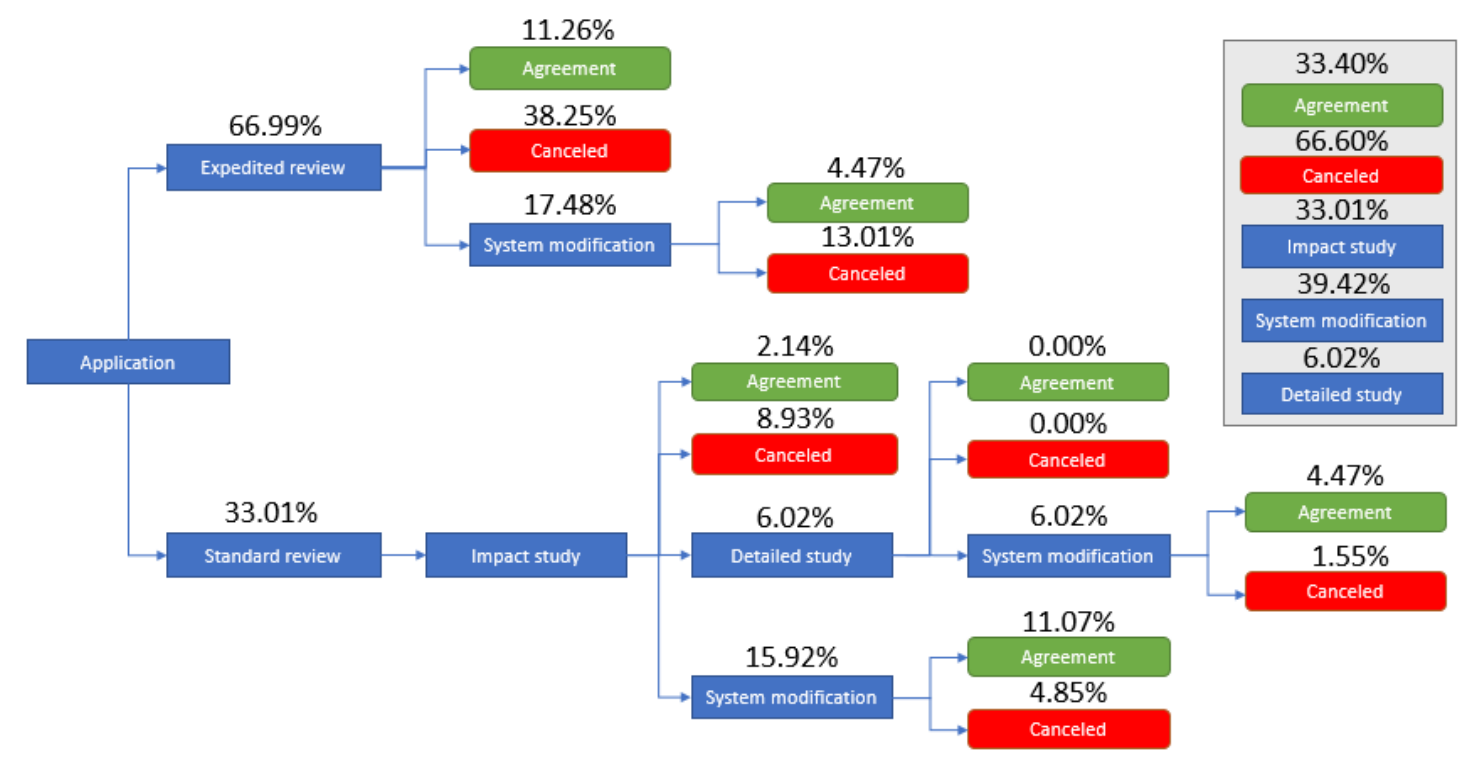

Figure 5. Interconnection pathways for projects $500 \mathrm{~kW}$ and larger with no pre-application report ( $N=515$, January 2009-May 2013)

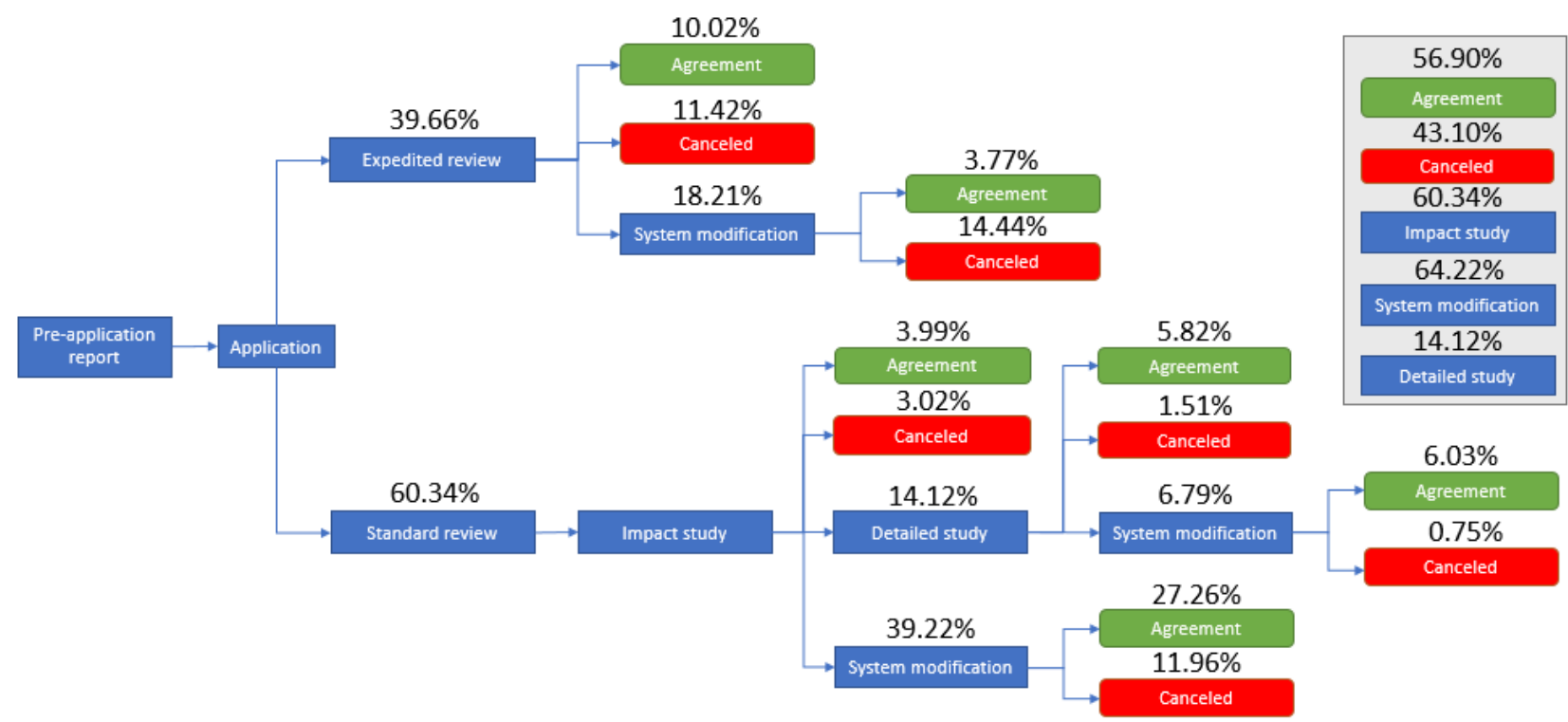

Figure 6. Interconnection pathways for projects $500 \mathrm{~kW}$ and larger with a pre-application report ( $N=928$, May 2013-April 2018)

Figure 7 breaks out how all the pathway percentages changed after pre-application report processes were implemented (calculated as the percentage in the pre-application case minus the percentage in the no-pre-application case). The percentage of projects undergoing Expedited review decreased by $27 \%$ after pre-application reports were implemented, and the percentage of projects undergoing Standard review increased by $27 \%$ accordingly. Overall the percentage of projects that reached agreement rather than cancelation increased $24 \%$ after pre-application reports were implemented, while the percentage of projects requiring a detailed study increased $8 \%$, and the percentage requiring system modification increased $25 \%$. Table 5 summarizes the results from Figure 5, Figure 6, and Figure 7. 
Table 5. Pathway Analysis Summary for Projects $\mathbf{5 0 0} \mathrm{kW}$ and Larger

\begin{tabular}{llll}
\hline & $\begin{array}{l}\text { Without pre- } \\
\text { application report } \\
\text { (\%) }\end{array}$ & $\begin{array}{l}\text { With pre- } \\
\text { application } \\
\text { report (\%) }\end{array}$ & $\begin{array}{l}\text { Difference } \\
\text { ("with" minus } \\
\text { "without") } \\
\text { (\%) }\end{array}$ \\
\hline Agreement & 33.40 & 56.90 & +23.50 \\
Canceled & 66.60 & 43.10 & -23.50 \\
Impact Study & 33.01 & 60.34 & +27.34 \\
System Modification & 39.42 & 64.22 & +24.81 \\
Detailed Study & 6.02 & 14.12 & +8.10 \\
\hline
\end{tabular}

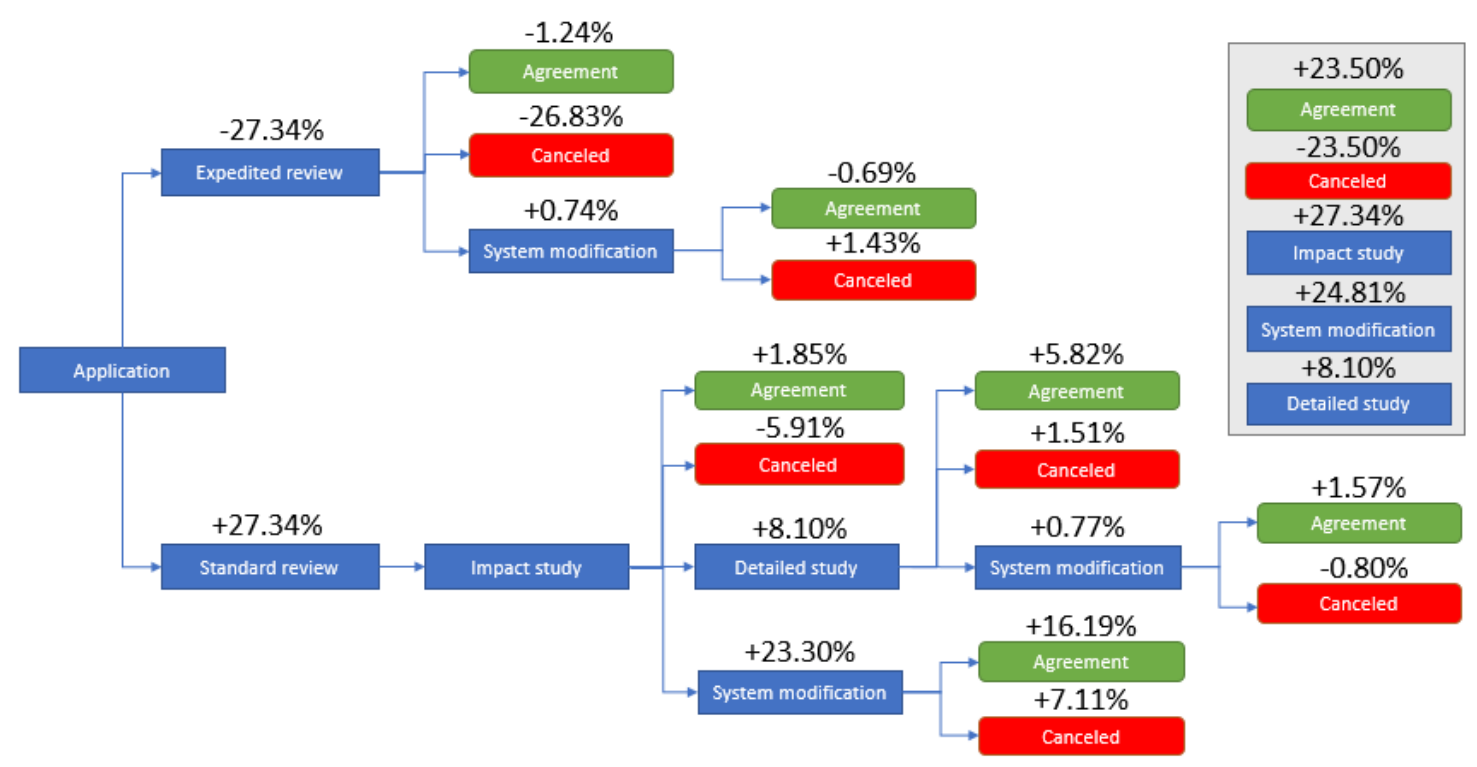

Figure 7. Changes in percentages of applications along each pathway after pre-application report processes were implemented (percentage in the pre-application case minus percentage in the nopre-application case) for projects $500 \mathrm{~kW}$ and larger 


\section{Discussion}

This section discusses the pathway results as well as data needed to enable further analysis.

\subsection{Pathway Results}

Pre-application reports processes were expected to decrease the percentage of canceled projects. The pathway analysis results support this hypothesis by demonstrating a significant $(24 \%)$ decrease in the percentage of canceled projects after pre-application report processes were implemented. For decision-makers seeking to improve interconnection processes, this is a meaningful result to consider. However, these results do not inform if pre-application reports improve the overall quality of applications, or if they simply reduce the amount of speculative applications. Further, it is difficult to say definitively that this improvement was caused by preapplication reports because it could be attributed to a number of factors. For instance, technological advancements may have improved the utility's ability to integrate DG, increasing the number of authorized projects. Similarly, lessons learned by project developers may have resulted in higher quality applications or improved processes for identifying optimal POIs (unrelated to pre-application reports). Additionally, projects that were previously cost prohibitive due to interconnection costs such as system modifications could now be feasible with the rapid decrease in PV system costs in recent years. It is possible all of these factors have played some role, in addition to pre-application reports.

An evaluation of the year-by-year change in percentage of approved projects (Table 6) further suggests that multiple factors likely play a role in the improvement of application approval rate. Table 6 illustrates how the percentage of approved applications increased (positive percentage) or decreased (negative percentage) from one year to the next. For example, the percentage of approved projects increased 9\% from 2009 to 2010, but decreased 21\% from 2010 to 2011 . Overall, the change in the percentage of approved applications varies widely from year to year. No significant trend is apparent for how approval rate is changing in the years prior to preapplication reports as the change in approved projects varies from positive to negative. In the years following pre-application report implementation, the change in approved projects is positive in all but one case. This continuous improvement in the application approval rate may be correlated to pre-application reports, but there is not enough evidence to suggest causation. 
Table 6. Year-to-Year Change in Percentage of Approved Applications

\begin{tabular}{|l|l|}
\hline Year to Year & Change \\
\hline $2009-2010$ & $+9 \%$ \\
\hline $2010-2011$ & $-21 \%$ \\
\hline $2011-2012$ & $-9 \%$ \\
\hline $2012-2013$ & $+10 \%$ \\
\hline $2013-2014$ & $+4 \%$ \\
\hline $2014-2015$ & $-5 \%$ \\
\hline $2015-2016$ & $+4 \%$ \\
\hline $2016-2017$ & $+11 \%$ \\
\hline $2017-2018$ & $+14 \%$ \\
\hline
\end{tabular}

The pathway analysis also highlighted how pre-application processes may be impacting the percentage of projects following each distinct review pathway. In the four years prior to preapplication reports, $67 \%$ of applications for projects $500 \mathrm{~kW}$ and larger underwent expedited review (33\% requiring standard review), but this fell to $40 \%$ (60\% standard review) in the five years following pre-application report implementation. The percentage of applications requiring detailed study and system modifications increased by $8 \%$ and $25 \%$, respectively, following preapplication report implementation. A variety of factors may have contributed to these shifts within the review pathways, such as increasing DG penetration or changes to review protocols. Thus, these results may or may not be directly caused by pre-application reports. By increasing grid transparency and encouraging interconnection at locations with little to no detrimental impact to the grid and low interconnection costs, it logically follows that pre-application reports may decrease the percentage of applications requiring a system modification or complex engineering review. However, the data do not reflect this trend-both the percentage of system modifications and detailed studies increase. The number of factors that impact the review pathway an application follows makes the direct impact of pre-application reports unclear. Future analyses may consider investigating this relationship further.

In-depth engineering studies increase the financial burden and processing time required from the utility and customer. If pre-application reports are increasing or decreasing the number of projects that typically need an in-depth engineering study, this would have an impact on interconnection costs. Similarly, by reducing the number of canceled projects, the sunk costs associated with canceled applications would also be reduced. The data considered lacked sufficient information to investigate these possibilities. Thus, a direct evaluation of preapplication report impact on interconnection costs was excluded in this analysis. The following section discusses specific data points that may help with analyzing the impact of pre-application reports on interconnection costs and other aspects of the interconnection process.

\subsection{Data Needs for Further Analysis}

This analysis represents a first step in the process of analyzing the impact of pre-application reports. The requirement for pre-application reports created a good natural experiment, and the pathway analysis here provides initial insights into what changes followed at a high level. 
However, as more decision-makers consider requiring pre-application reports, they may benefit from further studies that seek to more precisely establish a causal relationship between the preapplication reports and the outcome observed here, controlling for other potential factors. This section discusses opportunities to make those more causal linkages and would apply to decisionmakers who are considering pre-application report requirements or other similar interventions.

The ideal approach to a complex question like this one would be to run a well-designed regression to carefully assess how a variety of factors influence the outcomes, such as those Massachusetts stakeholders were seeking by instituting mandatory pre-application reports for projects above $500 \mathrm{~kW}$. The data that DOER collected and made available are an important first step towards a more robust data set that would facilitate more detailed analysis, but it is missing a few types of information. These gaps create a selection bias that makes effective regression analysis more challenging.

In this analysis, the selection bias likely skews the results to improve the approval rate after preapplication reports were implemented. For example, if a developer obtains three pre-application reports for three different circuits at the same time and decides on that basis to target one of the three, the data set only shows the one application that went ahead. There would be no data linking all of the pre-application reports with the application that proceeded. Similarly, if the same developer obtained multiple pre-application reports for a given circuit over time, there might be learning that is occurring at the developer about interconnection trends. This learning may inform future project design decisions but cannot be observed in the data as it is currently structured. In either of those cases, the developer may also choose to re-apply with a differently specified project that is not flagged as a revised application with reference to its original application.

Two primary sources of these gaps are 1) a lack of data identifying if an application received a pre-application report, and 2) a lack of data linking applications to the developers that submit them. Another related potential data point would note if the project is a revision to a prior project that was deemed to be a costly stress on a given circuit (i.e., a field that asks if a given application is a revision of a previous application). These data would likely need to be anonymized with a unique identifier in some way.

The additional data could be combined with several other categories of contextual information to more properly control for background factors that are valuable to control for in a regression analysis of pre-application report impact. Some of the data could be provided by an entity such as DOER, while others may require desk research or other sources. In addition to state-specific contexts and drivers for the DER industry, there are several categories of expanded data that would support effective analysis of pre-application reports:

1. Circuit-level data: Circuit information such as hosting capacity, voltage, and number of phases may aid in understanding why projects are integrated or canceled. While circuit conditions are dynamic, a snapshot of these at the time an application is submitted in conjunction with the project characteristics and can provide informative data. This could take a number of forms depending on data availability and regulatory requirements. As more jurisdictions pursue more expansive locational value methodologies, that 
information could be pulled into this analysis. Utilities are the primary sources for this information.

2. Utility and developer attributes: For both utilities and developers, information that can help assess learning over time would be a useful variable to control for in this analysis. For example, changes in a given utility's staffing levels or the amount of resources it can dedicate to interconnection processing could impact interconnection application results and costs. Data identifying the amount of resources (time and money) put towards interconnection applications over time can help identify when learning may be occurring.

3. Interconnection costs: Project-level cost information for system modifications and engineering studies would assist in improving project planning processes. Ideally, this information would be provided by utilities and developers. Through analysis of this data the relative uncertainty of these costs may be reduced. While these costs are dependent on system conditions, this data could be useful when associated with the project characteristics and circuit characteristics when the application was submitted. Ultimately, the data could be used to identify trends that may reduce financial risk for project developers, thus reducing overall interconnection costs. Increased clarity of the dynamics of interconnection costs may aid in quantifying the impact of pre-application processes.

4. National interconnection data: Ideally, all the above data points would be provided by multiple states with varying regulatory structures. Expanding this analysis to include data beyond the Massachusetts market would help to validate that the impacts of preapplication report processes are not limited by nuances within individual states and thus can be widely applied. Entities such as DOER could assist with compiling and publishing this data to provide a central access point and maintain data privacy. 


\section{Conclusions}

New methods are being pursued throughout the country to improve interconnection processes and the transparency of grid integration. Pre-application report processes are one such method that has been deployed in multiple states towards these ends. In theory pre-application report processes provide a relatively low-cost, low-effort method for improving the interconnection process. This report analyzes the impact pre-application reports have on improving application approval rate.

The analysis found that pre-application reports are correlated with an increase in application approval rate. ${ }^{4}$ Following the implementation of pre-application report processes, the percentage of projects $500 \mathrm{~kW}$ and larger being canceled decreased $24 \%$. During the analysis timeframe a notable shift was also observed in the review pathways followed for projects $500 \mathrm{~kW}$ and larger. The percentage of projects following the expedited review path decreased by $27 \%$. The percentage of projects requiring a system modification and detailed study both increased by $25 \%$ and $8 \%$ respectively. This trend towards applications requiring more complicated reviews may or may not be correlated with pre-application reports. Additional data and analyses are needed to better characterize this relationship.

The analysis is unable to conclude direct causation between pre-application reports and the increased application approval rate. This is primarily due to the multitude of factors impacting application approval and gaps in available interconnection data. In particular, the data were subject to selection bias due to the fact that no data exist for when a project is canceled based on the information contained in a pre-application report prior to a formal application submission. Data expanding upon the current set to clarify issues such as this can help to overcome these challenges. In addition, data such as utility/developer attributes and circuit-level data can expand the analysis to provide a more robust understanding of how pre-application reports and other measures are affecting the interconnection process.

As the complexity of the grid continues to grow, so does the need to manage that complexity. Tools such as pre-application reports may aid in improving interconnection processes, but it is important to measure their impact in practice to verify they are resulting in the intended consequences. Decision-makers that wish to improve interconnection processes through evidence-based analysis require data that provide sufficient context and facilitate measurement of these tools.

${ }^{4}$ There are also other factors that are correlated with application approval rate, such as maturity of the marketplace. 


\section{References}

Ardani, Kristen, and Robert Margolis. 2015. Decreasing Soft Costs for Solar Photovoltaics by Improving the Interconnection Process: A Case Study of Pacific Gas and Electric. Golden, CO: National Renewable Energy Laboratory. https:/www.nrel.gov/docs/fy15osti/65066.pdf

Bingham, Gerry. 2018. "Pre-Application Report Analysis,” June 7, 2018.

Coddington, M., K. Fox, S. Stanfield, L. Varnado, T. Culley, and M. Sheehan. 2012. Updating Small Generator Interconnection Procedures for New Market Conditions. Golden, CO: National Renewable Energy Laboratory. NREL/TP-5400-56790. https://doi.org/10.2172/1060613.

DOER (Division of Energy Resources, Commonwealth of Massachusetts Office of Consumer Affairs and Business Regulation). 2002. 2000 Market Monitor: Electric Industry Restructuring. http://www.mass.gov/eea/docs/doer/electric-deregulation/mm3.pdf

DOER (Massachusetts Department of Energy Resources). 2018. Interconnection https://sites.google.com/site/massdgic/home/interconnection

DSIRE (Database of State Incentives for Renewables \& Efficiency). 2017a. Net Metering. Accessed March 26, 2017. http://programs.dsireusa.org/system/program/detail/281

DSIRE (Database of State Incentives for Renewables \& Efficiency). 2017b. Renewable Portfolio Standard. Accessed March 26, 2017. http://programs.dsireusa.org/system/program/detail/479

Fu, Ran, David Feldman, Robert Margolis, Mike Woodhouse, and Kristen Ardani. 2017. U.S. Solar Photovoltaic System Cost Benchmark: Q1 2017. Golden, CO: National Renewable Energy Laboratory. Technical Report NREL/TP-6A20-68925.

https://www.nrel.gov/docs/fy17osti/68925.pdf.

Massachusetts Distributed Generation Interconnection Working Group. 2012. Proposed Changes to the Uniform Standards for Interconnecting Distributed Generation. http://massdg.raabassociates.org/Articles/Final\%20MA\%20DG\%20WG\%20Report\%209-1412.pdf

National Grid. 2016. Interconnection Tariff https://www9.nationalgridus.com/non html/Interconnect stds MA.pdf

The Commonwealth of Massachusetts Department of Public Utilities. 2013. D.P.U. 11-75-E, Investigation by the Department of Public Utilities on its own Motion into Distributed Generation Interconnection. http://massdg.raabassociates.org/Articles/DPU\%2011-75-E-3-1313.pdf

The Commonwealth of Massachusetts Department of Telecommunications \& Energy. 2005. Massachusetts Department of Telecommunications and Energy 2005 Annual Report. http://archives.lib.state.ma.us/bitstream/handle/2452/264008/ocm469146432005.pdf?sequence $=1 \&$ is Allowed $=y$ 
U.S. Energy Information Administration. 2017. Form EIA-861M. Monthly Electric Power Industry Report. Washington, D.C.: U.S. Energy Information Administration. https://www.eia.gov/electricity/data/eia861m/

U.S. Federal Energy Regulatory Commission. 2013. Small Generator Interconnection Agreements and Procedures. 18 CFR Part 35. https://www.ferc.gov/whats-new/commmeet/2013/112113/E-1.pdf 


\section{Appendix A. National Grid Pre-application Request}

Massachusetts Electric Company \& Nantucket Electric Company (d/b/a National Grid)

MD.P.U. 1320

Exhibit B - Generating Facility Expedited/Standard Pre-Application Report Form

Contact Information (TVPE or PRINT:

Date Prepared:

Legal Name and Address of Interconnecting_Customer

Interconnecting Customer:

Contact Person:

Mailing Address:

City: State:

Zip Code:

Telephone (Daytime): (Evening):

Facsimile Number: E-Mail Address:

Altemative Contact Information (e.g., system installation contractor or coordinating company, if appropriate):

Company Name: Contact Person:

Mailing Address:

City: State: Zip Code:

Telephone (Daytime):

Facsimile Number: (Evening): E-Mail Address:

\section{Facility Information (TYPE or PRINT):}

Proposed Facility Lecation

Address of Facility:

Nearest Cross Street/Intersection:

City: State: Zip Code:

GPS Coordinates: (North) (West)

Please attach a map or overhead picture from an online mapping website (e.g. Google Maps, Bing Maps) with the proposed location clearly marked, North indicated (if not at the top), and at least one cross street visible (if possible).

Generation Type

Prime Mover: $\square$ Photovoltaic $\square$ Reciprocating Engine $\square$ Fuel Cell $\square$ Turbine $\square$ Other: Energy Source: $\square$ Solar $\square$ Wind $\square$ Hydro $\square$ Diesel $\square$ Natural Gas $\square$ Fuel Oil $\square$ Other:

Size (AC) \& Generator Phase System Design Capacity: $\left(\mathrm{kW}_{\mathrm{AC}}\right)$ (kVA)

Single $\square$ or Three $\square$ Phase

Stand-alone

Is there any on-site load (not including parasitic load)? $\quad \square$ Yes $\square$ No

Existing Service

If there is existing service at the Proposed Facility site (e.g. on the same parcel of land), provide: Account Number:

If available, the site minimum and maximum current (or proposed) electric loads:

Minimum $\mathbf{k W}$ : Maximum $\mathrm{kW}$ :

New or Ungraded Service

Is a new service or service upgrade needed? $\quad \square$ Yes $\square$ No

Instructions: Email the completed form (along with any additional notes) to Distnbuted.Generation@nationalgrid.com. DISCLAIMER: Be aware that this Pre-Application Report is simply a snapshot in time and is non-binding. System conditions can and do change frequently.

Massachusetts: http://www.nationalgridus.com/masselectric/home/energyeff/distributed generation.asp Nantucket: http://wwwnnationalgridus.com/nantucket/home/energyeff/distributed generation asp 


\section{Appendix B. DOER Monthly Interconnection Reporting Raw Data Fields}

\begin{tabular}{|c|}
\hline Company Name \\
\hline City/Town \\
\hline Facility ID (if any) \\
\hline ZIP Code \\
\hline Design Capacity (kW) \\
\hline Fuel Type (Solar, Wind, etc.) \\
\hline Circuit Name \\
\hline Date Application Received \\
\hline Date Application Deemed Complete \\
\hline Total Time Lapsed (Workdays) calculated value \\
\hline Customer Time Lapsed (Workdays) enter workdays of "clock" stoppage by Customer \\
\hline Utility Time Lapsed (Workdays) enter workdays without "clock" stoppage \\
\hline Date Review of Screens Study Begun \\
\hline Date Review of Screens Study Completed \\
\hline Total Time Lapsed (Workdays) calculated value \\
\hline Customer Time Lapsed (Workdays) enter workdays of "clock" stoppage by Customer \\
\hline Utility Time Lapsed (Workdays) enter workdays without "clock" stoppage \\
\hline Date Supplemental Review Begun \\
\hline Date Supplemental Review Complete \\
\hline Total Time Lapsed (Workdays) calculated value \\
\hline Customer Time Lapsed (Workdays) enter workdays of "clock" stoppage by Customer \\
\hline Utility Time Lapsed (Workdays) enter workdays without "clock" stoppage \\
\hline
\end{tabular}




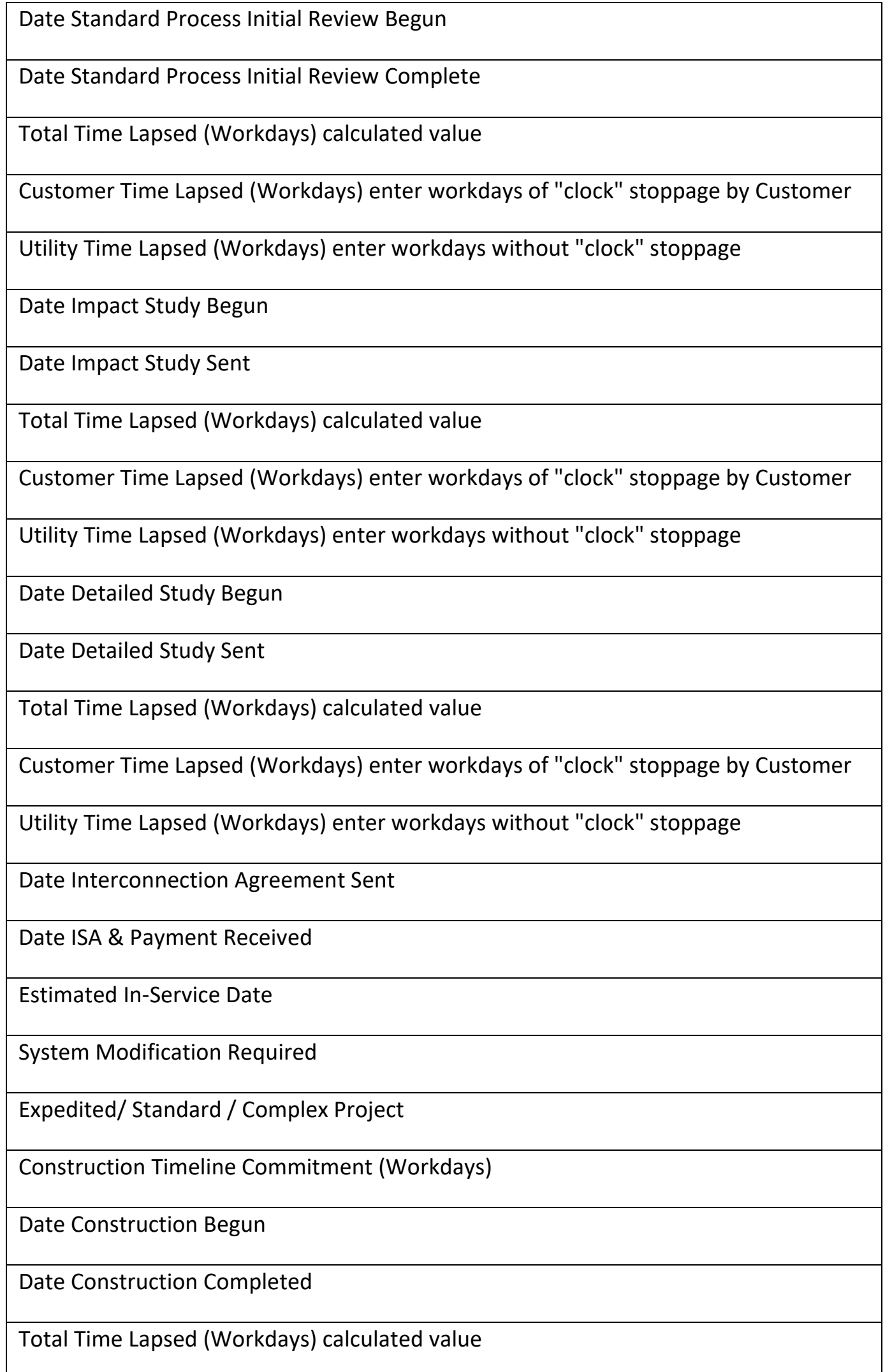




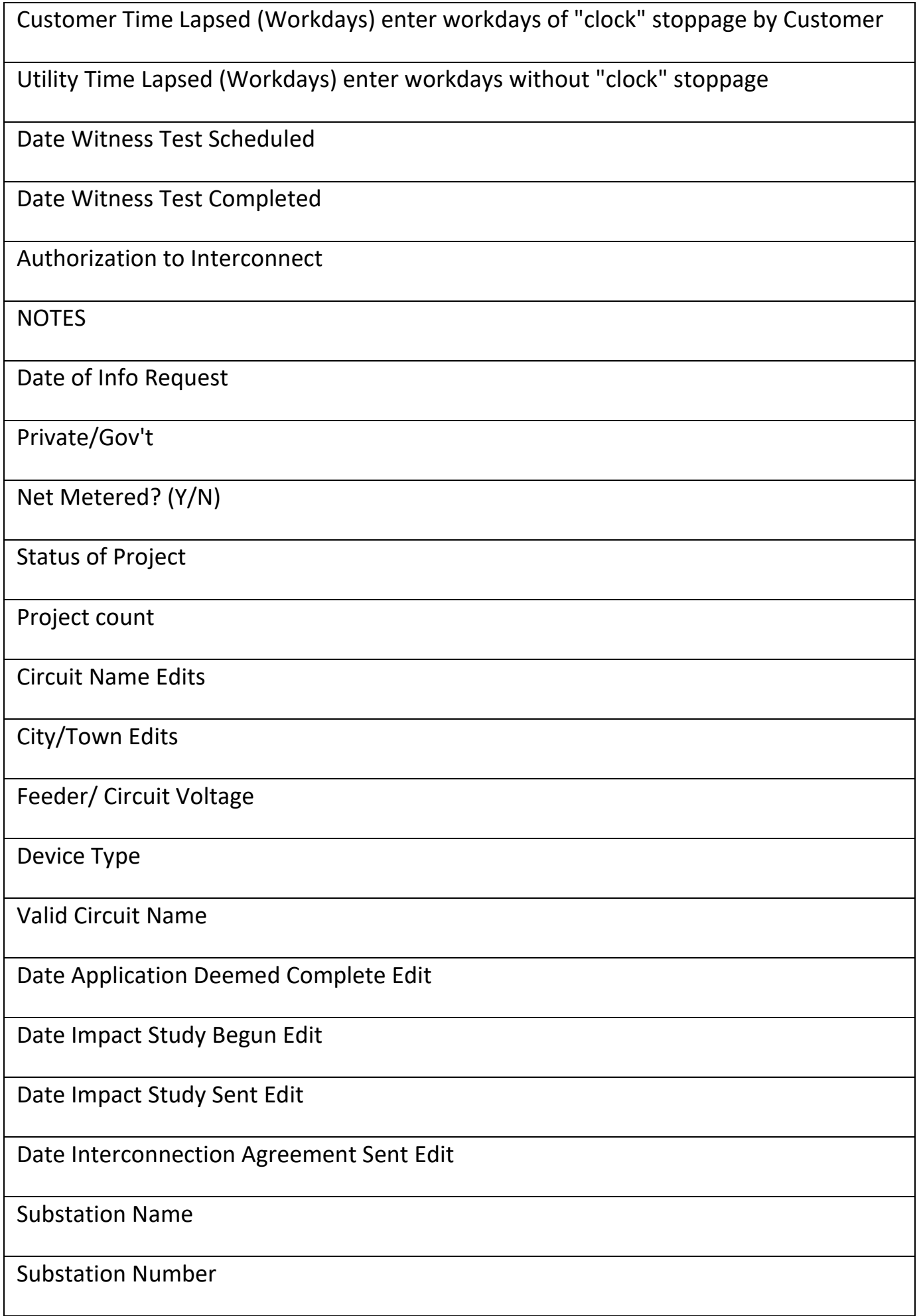




\section{Appendix C. DOER Interconnection Data Cleaning}

\begin{tabular}{|l|l|l|}
\hline Column Name & Description & Data Cleaning \\
\hline $\begin{array}{l}\text { Fuel Type (Solar, } \\
\text { Wind, etc.) }\end{array}$ & Fuel type for project & $\begin{array}{l}\text { Delete all rows excluding PV, PV \& Battery, Solar, and } \\
\text { Solar and Battery }\end{array}$ \\
\hline $\begin{array}{l}\text { Design Capacity } \\
\text { (kW) }\end{array}$ & $\begin{array}{l}\text { Design capacity (kW) } \\
\text { for application }\end{array}$ & Select blank entries and delete corresponding rows \\
\hline $\begin{array}{l}\text { Date Application } \\
\text { Deemed Complete }\end{array}$ & $\begin{array}{l}\text { Date application } \\
\text { deemed complete by } \\
\text { utility }\end{array}$ & $\begin{array}{l}\text { Select blank and erroneous (i.e., 1/1/1900), then delete } \\
\text { corresponding rows }\end{array}$ \\
\hline $\begin{array}{l}\text { Date Impact Study } \\
\text { Begun }\end{array}$ & $\begin{array}{l}\text { Date Impact Study } \\
\text { Begun }\end{array}$ & Blank cells changed to "(blank)" \\
\hline $\begin{array}{l}\text { Date Detailed } \\
\text { Study Begun }\end{array}$ & $\begin{array}{l}\text { Date Detailed Study } \\
\text { Begun }\end{array}$ & Blank cells changed to "(blank)" \\
\hline $\begin{array}{l}\text { System } \\
\text { Modification } \\
\text { Required }\end{array}$ & $\begin{array}{l}\text { States if system } \\
\text { modification is } \\
\text { required }\end{array}$ & $\begin{array}{l}\text { Blanks changed to "no", "N" changed to "no", "na" } \\
\text { changed to "no", "n/a" changed to "no". Removed } \\
\text { applications with "tbd", "withdrawn" and "m" }\end{array}$ \\
\hline Status of Project & Project status & Remove "2 - In Process" projects \\
\hline
\end{tabular}

Data Source: https://sites.google.com/site/massdgic/home/interconnection > Raw data for April 2018, posted May 21, 2018. 


\section{Appendix D. Massachusetts Interconnection Process}

\section{STANDARDS FOR INTERCONNECTION OF DISTRIBUTED GENERATION}

Figure 1 - Schematic of Massachusetts DG Interconnection Process

Interconnecting Customers with Facilities that are $500 \mathrm{~kW}$ or greater shall request a Pre-Application Report.

Interconnecting Customer submits complete Simplified Interconnection Application (Exhibit $\mathrm{A}$ and attachments)

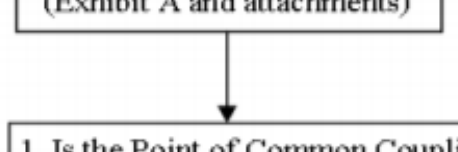

Interconnecting Customer submits complete Expedited/Standard Interconnection Application (Exhibit $\mathrm{C}$ and attachments) and Application Fee

Interconnecting Customer opts to forego the Expedited Process and have application reviewed under Standard Process

1. Is the Point of Common Coupling on a radial distribution system?

$$
\downarrow \text { Yes }
$$

2. Is the aggregate generating Facility capacity less than $15 \%$ of feeder/circuit annual peak load and, if available, line segment? (Note 1)

$$
\downarrow \text { Yes }
$$

3. Does the Facility use a listed inverter (UL 1741)?

4. Is the Facility power rating $<15 \mathrm{~kW}$ singlephase or $<25 \mathrm{~kW}$ three-phase?

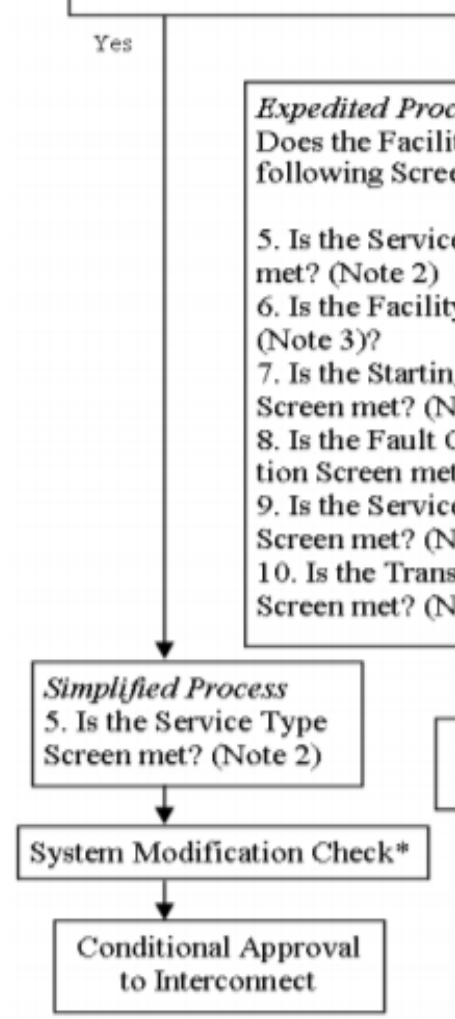

$$
\text { No }
$$

ses

Expedited Process

Does the Facility pass all the (Note 2)

Facility Listed per

Voltage Drop

Fault Current Contribu-

Configuration

Transient Stability
Simplified Proces.

is the Service Type

Screen met? (Note 2)

System Modification Check*

Conditional Approval to interconnect
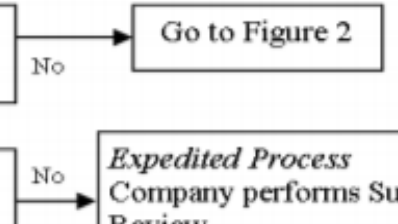

Expedited Process

Company performs Supplemental Review

Does the Facility pass all the following Screens?* (Note 8)

A. Penetration test

B. Power quality \& voltage test

C. Safety \& reliability test

No Are System Modification requirements determined without further study"?

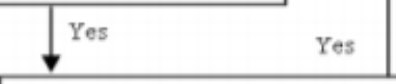

Are System Modifications required?

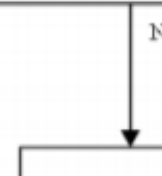

Standard

Process

Initial

Review

*Only if required

If a Detailed Study is required, the Interconnecting Customer may request an Interconnection Service Agreement before the Detailed Study is completed. Refer to Section 3.4. 